Revista de Estudios Histórico-Jurídicos

[Sección Historia del Derecho Indiano]

XXXVI (Valparaíso, Chile, 2014)

[pp. 245 - 269]

\title{
Corregidores sin Corregimientos: Un CASO de mestizaje instituCiOnal EN SANTA Fe del Río de la Plata dURAnTe los Siglos XVII y XVIII
}

[Corregidores without Corregimientos:

A Case of Institutional Mixture in Santa Fe del Río de la

Plata in the 17th - 18th Centuries]

\author{
Darío BARRIERA* \\ Universidad Nacional de Rosario, Argentina
}

\begin{abstract}
RESUMEN
La particular implementación de la figura del corregidor en la ciudad de Santa Fe y su jurisdicción durante los siglos XVII y XVIII permite revisitar un problema que signó y hasta desveló a la historia institucional del gobierno colonial: realidades locales que no encajaban perfectamente en su descripción normativa. Este artículo propone analizar el problema evitando la opción de un divorcio entre "normas y prácticas": parte de asumir que las realidades jurídicas constituyen un insumo con el cual los agentes construyeron instituciones de gobierno y justicia en el Río de la Plata colonial. Para alcanzar el objetivo, expone una bitácora del funcionamiento de esta figura institucional mostrando al mismo tiempo
\end{abstract}

\begin{abstract}
The peculiar implementation of the corregidor figure in the city of Santa $\mathrm{Fe}$ and their jurisdiction in the $17^{\text {th }}$ and $18^{\text {th }}$ centuries allows us readdress a problem that marked and even unveiled the institutional history of the Colonial government: local realities that did not quite match their normative description. This article proposes to analyze the problem by avoiding a divergence between "norms and practices": it begins by assuming that legal realities are an input with which the agents built government and justice institutions in Colonial Río de la Plata. In achieving this objective, we outline a log concerning how this institutional figure operated by showing, at the same time, how the Castilian legal
\end{abstract}

RECIBIDO el 20 de abril y ACEPTADO el 26 de julio de 2014

* Profesor titular ordinario de Historia colonial de América en la Universidad Nacional de Rosario; investigador independiente del Consejo Nacional de Investigaciones Científicas y Técnicas. Dirección postal: Montevideo 1749, Piso 2 (2000) Rosario, Argentina. Correo electrónico: dgbarriera@conicet.gov.ar 
de qué manera los componentes jurídicos castellanos adquirieron una significación singular y mestiza pero legal y funcional en una experiencia concreta de gobierno.

Palabras Clave

Corregidor - Alcaldes mayores - Mestizaje institucional . components gained a singular and mixed, though legal and functional, meaning in a government's practical experience.

KEYworDS
Corregidor - Alcaldes mayores - Insti-
tutional Mixture.

\section{INTRODUCCIÓN**}

No es inusual que, para satisfacer una consulta, estudiantes o colegas requieran del insumo de una historia de las instituciones. En los tiempos que corren, además, exigirán de la misma que se haya contrastado el deber ser de lo prescripto con la experiencia concreta. En este contexto recogí algunos interrogantes sencillos cuya respuesta no soporta el mismo calificativo ni se agota en la brevedad de una frase, ni en la extensión de este artículo: ¿hubo corregidores en la ciudad de Santa Fe del Río de la Plata? ¿Su presencia o su ausencia en la constelación de oficios políticos coloniales expresan un síntoma en la organización institucional del cuerpo político que contiene a la ciudad? ¿Hay diferentes tipos de corregidores? ¿Puede que un indio haya sido corregidor? Y finalmente: si hubo corregidores en Santa Fe, ¿por qué no existió en cambio, como en el Perú, Nueva España, Chile o Cuyo, el corregimiento?

En su simpleza, estos interrogantes sintetizan problemas generales que subyacen a la mirada desde la cual se plantea aquí una práctica fragmentaria de la historia de una institución: para ofrecer una respuesta constructivista deben estudiarse las creaciones jurídicas pero también las agencias que muestran el vínculo entre el gobierno de los hombres y el artificio de las instituciones en su historicidad. Esto, forzosamente, implica plantearse el problema general en una o varias escalas locales. Siguiendo las sugerencias de Yan Thomas, trataré de confeccionar esta historia con los materiales que sirvieron "[...] para fabricar las cosas institucionales de las cuales son formadas las organizaciones sociales" 1 .

Este ejercicio, aunque ofrecido sobre una periodización extensa, se enfoca en una sede de poder político muy concreta. Las respuestas que la problematización del tema propone al puñado de preguntas ingenuas con el cual inicia esta introducción están fabricadas con materiales jurídicos pero, en el intento de evitar una historia reificación de las ideas o de las doctrinas, apelando al carácter performativo del derecho, he apelado también y sobre todo a testimonios directos de los agentes encargados de constituir y hacer funcionar los artefactos institucionales en una realidad que, antes que una tabula rasa, era una escena dinámica, acto de una

** Abreviaturas: $\mathrm{AC}=$ Actas Capitulares; AGSF = Archivo General de la provincia de Santa Fe, Argentina; $\mathrm{BN}=$ Biblioteca Nacional, Buenos Aires, Argentina.

${ }^{1}$ Thomas, Yan, El artificio de las instituciones (Buenos Aires, Ediciones de la Universidad de Buenos Aires, 1999), p. 12. 
obra en pleno desarrollo donde la irrupción de nuevos actores, nuevos elementos escenográficos o de nuevos guiones no permitía barajar y dar de nuevo.

Se movilizarán entonces testimonios doctrinales e información generada por la acción concreta de gobernantes y gobernados en Santa Fe del Río de la Plata entre los años 1573 y 1799. La dificultosa construcción de una casuística pormenorizada se realizó apelando a archivos locales, lo cual permite presentar especificidades poco conocidas que, se espera, enriquecerán el fabuloso mosaico de originalidades que presenta la historia del gobierno de los territorios bajo el dominio de la Monarquía hispánica entre los siglos XVI y XIX.

\section{Corregidores y ALCALDES MAYORES:}

\section{UNA CONFUSIÓN FRECUENTE EN LA HISTORIOGRAFÍA AMERICANISTA}

Es de sobra conocida la confusión que existe entre estos oficios para el gobierno colonial $^{2}$. En un libro clásico sobre las instituciones sociales, económicas y jurídicas de la América hispánica colonial, describiendo la articulación de autoridades entre la ciudad y sus jurisdicciones superiores, José María Ots Capdequí escribió: “Al frente de las ciudades importantes figuró otro funcionario, representante en la ciudad del poder del Estado, con el nombre de alcalde mayor en unas regiones y en otras de corregidor" 3 .

Ots atribuía la diferencia en el nombre a variaciones regionales en la forma de designar a un mismo funcionario de justicia y gobierno. En la obra también muy difundida de Stanley J. Stein y Barbara H. Stein, puede leerse en varias ocasiones "corregimiento o alcaldía mayor..." así como "alcalde mayor o corregidor", sin perjuicio de referirse, respectivamente, al distrito o al funcionario de españoles o al de indios ${ }^{4}$. Expertos en Historia del Derecho plantearon que ambas figuras tuvieron mucho en común ${ }^{5}$ y otros historiadores de perspectiva disciplinar más ancha, como Guillermo Lohmann Villena, afirmaron que dicha coincidencia alcanzó un punto tal que en ciertos contextos su distinción podría caracterizarse como meramente accidental. Este autor sugiere que no debió ser “[...] fácil para

${ }^{2}$ Para Cruz Barney, Óscar, Derecho indiano local: el reglamento provisional para las milicias del Real del Mazapil de 1786, en AMHD., 22 (México, 2010), p. 101, la confusión se habría provocado entre alcaldes mayores y tenientes de gobernador, aunque da por zanjado el problema hacia 1536. Este autor, no obstante su tendencia a generalizar, introduce el diferente impacto regional de "la institución de los alcaldes mayores [que] se generaliza y arraiga en la Nueva España, no así en el Perú. Existían, además, los alcaldes mayores de audiencia a imitación de los alcaldes mayores del reino, surgidos en España, específicamente en Galicia”.

${ }^{3}$ Ots Capdequí, José María, El estado español en las indias (México, Fondo de Cultura Económica, 1957), p. 75.

${ }^{4}$ Es nítido este pasaje: “Allí se encontraba el corregidor de indios o alcalde mayor, un español letrado de educación legal generalmente limitada que había comprado su nombramiento [...]": Stein, Stanley J. - SteIn, Barbara H. La herencia colonial de América Latina (1970, México, Siglo XXI, 1970), pp. 76-77.

${ }^{5}$ García Gallo, Alfonso, Alcaldes mayores y corregidores en Indias, en Estudios de derecho indiano (Madrid, 1972). 
los tratadistas dilucidar las características peculiares de cada uno de esos oficios"6. Acierta el historiador limeño si se piensa en algunos casos célebres: el gran Solórzano llegó a decir que, en América, se trataba del mismo oficio con distinto nombre -sobre todo cuando se trataba de la magistratura asociada a "de indios"

Entre sus atributos tenían en común el constituirse como justicias mayores en sus distritos; el que aparecen en la nomenclatura de mandatarios coloniales desde la década de 1520 y el que los designaran autoridades ya radicadas en América, frecuentemente sin esperar a que lo hiciera algún organismo metropolitano. La Real Audiencia de Nueva España autorizó los primeros corregidores en 1530, la del Perú en 1548 y en los años 1550 surgieron ya los corregidores y alcaldes mayores de pueblos de indios, duplicando entonces cierta confusión para el territorio americano que surgía del afán de hacer gobierno en las tierras nuevas dotando de institucionalidad a las diferentes relaciones que se entablaban entre los conquistadores y entre estos y los conquistados ${ }^{8}$. Muchos son los tratados sobre el arte de gobernar las indias que se refieren a los corregidores como gobernadores o reflexionan sobre estos oficios indistintamente 9 . Parece innecesario decir que, además, los trata como oficiales de gobierno y justicia -funciones que, aunque separables, iban profundamente ligadas en la delegación de jurisdicción ${ }^{10}$.

Sin embargo, en las leyes de Castilla como en las recopiladas para las Indias

${ }^{6}$ Lohmann Villena, Guillermo, La nueva estructura politica, en Pease, Franklin - Frank Moya Pons (directores), El primer contacto y la formación de nuevas sociedades. Historia Ggneral de América Latina (Madrid, Unesco - Trotta), II, p. 469.

${ }^{7}$ García Gallo, Alfonso, Alcaldes, cit. (n. 5).

${ }^{8}$ Esta historia está muy bien contada por Juan de Solórzano y Pereyra, en el libro II, capítulo $27^{\circ}$ de su Política Indiana.

${ }^{9}$ En estos términos se plantea la equivalencia funcional de corregidores con gobernadores (y a partir de casos específicos: los corregidores novohispanos con los gobernadores rioplatenses, i.e.). Cfr. Trujillo, Oscar J., Consenso, negociación y conflicto en la Monarquía Hispánica: La élite de Buenos Aires en el XVII (Tesis de doctorado, Luján, Univ. Nacional de Luján, 2013, inédit), p. 231. Respalda este uso la práctica coetánea. Rafael Altamira y Crevea lo explicó señalando como gobernadores a todos aquellos que desempeñaban "[...] un grado de mando inferior y subordinado al virrey; pero también se aplicó a ese mismo jefe supremo [...]”: ALtAMIRA y CREVEA, Rafael, Autonomía y descentralización legislativa en el Régimen colonial español. Siglos XVI y XVIII (Buenos Aires, Instituto de Investigaciones de Historia del Derecho, 2011), p. 156 n. 152.

${ }^{10}$ Lo cual puede estar en la base de la composición que expresaba Florian Paucke (¡o su traductor?), Hacia allá y para acá, Memorias (trad. de Edmundo Wernicke y edición de Agustín Alzari, Santa Fe, Ministerio de Innovación y Cultura, 2010), p. 102 cuando escribió: "Los corregidores que los españoles llaman alcaldes se cambian anualmente tanto en España como en Indias". El autor claramente se refirió en esta ocasión a los alcaldes de primer y segundo voto; el párrafo de la página siguiente, donde alterna corregidores con alcaldes como equivalentes ("corregidores" lo utiliza como descriptivo y alcaldes en itálica, indicando que en original alemán figuraba ya en español), así como una mención en la página 137 “[...] dos corregidores de la ciudad o alcaldes...” todo lo cual nos inclina a adjudicar la confusión al traductor. Cuando Paucke se refirió al corregidor de indios del Perú, lo hizo en español en la edición original y no hay posibilidad de equívoco. En su obra no hay menciones a corregidores indios -y según mi presunción esto no sería una oclusión, ya que aparecen mencionados en registros capitulares solo a finales de la década de 1770-. 
Occidentales, existen elementos jurídicos para distinguir claramente entre ambos oficios desde temprano ${ }^{11}$.

Entre los tratadistas más reconocidos que se ocuparon del tema, Castillo de Bovadilla ${ }^{12}$ dejó testimonio de esa claridad y reconocía en los corregidores a jueces-gobernadores legos o de capa y espada, a los cuales advertía reiteradamente su deber de acudir al consejo de los sabios en materias de gobierno y de los letrados en la de justicia, refiriendo que dicha obligación se remontaba a las Partidas alfonsinas. Hunde la genealogía de esta figura en los tiempos de Roma ${ }^{13}$ y resalta cómo, en España, los corregidores dejaron de ser comisarios enviados por una autoridad superior y, desde los tiempos de los Reyes Católicos: "[...] se envían a las ciudades y villas destos reynos Corregidores por gobernadores y juezes ordinarios dellas con plenissima jurisdición por tiempo de un año y suele prorrogarse dos y tres, y más años, a voluntad de los Reyes y hasta que ellos embian otros en su lugar" 14 .

Castillo de Bovadilla distinguía claramente entre corregidores y alcaldes mayores: recomendaba que los primeros fueran completamente externos a la comunidad, maximizando la distancia social allí donde disminuía la física ${ }^{15}$, así como admitía y sugería que los asesores letrados fueran locales ("vecino y natural del pueblo") e incluso lo aconsejaba en poblaciones pequeñas, puesto que aseguraban entonces el conocimiento de las costumbres del pueblo. Durante este periodo, anterior al decreto de primero de octubre de 1783 sobre la nueva Planta y Escala de Corregimientos y Alcaldías Mayores de los Reinos de Castilla y Aragón e Islas adyacentes, claro está, la condición letrada aún no era exigible para los corregidores.

Para el caso del gobierno de los territorios americanos, la ley primera del primer título del quinto libro de la Recopilación de 1680 distinguía a los alcaldes mayores como los administradores de justicia designados en ciudades que no eran sede de

${ }^{11}$ El título cuarto del libro IV de los Sumarios reunía una serie de reales cédulas que clarificaban estas distinciones bajo el título "De los gobernadores, corregidores, alcaldes mayores de las Indias y sus tenientes”, f. 339 ss. Este título recoge claramente la designación diferenciada de gobernadores, corregidores y alcaldes mayores en diferentes distritos. Tenían en común la duración de sus designaciones en Indias (tres años, ley 18) y varios derechos (a no ser removidos sino por el rey) y prohibiciones (echar mano de las cajas de los pueblos de indios) que pesaban sobre ellos por igual. Sobre el corregidor castellano y su introducción como cuña del poder regio en los concejos en el marco de un proceso de centralización del poder regio, cfr. las hipótesis clásicas en BERMúdez AzNAR, Agustín, El corregidor en Castilla durante la Baja Edad Media (1348-1474) (Murcia, 1974); MITRE, Emilio, La extensión del régimen de corregidores en el reinado de Enrique III de Castilla (Valladolid, 1969); y GonZÁlez Alonso, Benjamín, El corregidor castellano (1348-1808) (Madrid, Siglo XXI, 1970).

${ }^{12}$ Castillo de Bovadilla, Jerónimo, Politica para corregidores y señores de vasallos, en tiempos de paz y de guerra (1599, Amberes, 1704), libro I, cap. $12^{\circ}$.

${ }^{13}$ Covarrubias lo definió en 1611 como "[...] el que rige y gobierna alguna ciudad o pueblo, latine praetor", DE COVARRUBIAS, Sebastián, Tesoro de la lengua castellana o española (1611, Barcelona, Alta Fulla, 1998), p. 363.

${ }^{14}$ Castillo de Bovadilla, Jerónimo, Política, cit. (n. 12), tomo I, libro I, cap. $1^{\circ}$, p. 22.

${ }^{15}$ BARRIERA, Darío G., Entre el retrato jurídico y la experiencia en el territorio. Una reflexión sobre la función distancia a partir de las normas de los Habsburgo sobre las sociabilidades locales de los oidores americanos, en Caravelle, 101 (Toulouse, dec. 2013), pp. 133-154. 
gobernación ni de corregimiento, por lo tanto no recomendaba su solapamiento, sino todo lo contrario.

Años más tarde, las definiciones de Joaquín de Escriche, magistrado de la Audiencia de Madrid, constituyen un testimonio que carga con toda la fuerza de su propio presente la jerarquía histórica de dichas distinciones, ubicando al alcalde mayor en un lugar de privilegio respecto de la justicia que él mismo representa y reconoce como punto más alto de la organización judicial, es decir, la justicia ordinaria letrada. Para el autor del Diccionario razonado, el alcalde mayor era un "[...] juez de letras que ejercía la jurisdicción ordinaria en algún pueblo o partido" y reconocía que también se llamaba así al "[...] que había en las ciudades donde el corregidor era un lego, a quien tenía que servir de asesor. Ahora el alcalde mayor se llama juez letrado de primera instancia”. Expone claramente la función pedagógica y paladina que suponía la designación de estos letrados allí donde “[...] había solo corregidores militares o de capa y espada [...] para evitar el gravamen que sufrían los habitantes con los derechos de asesorías" ${ }^{\text {". }}$. En lo que concierne a los corregidores, la definición apunta a lo que significaban en el siglo XIX, pero establece su situación de inferioridad respecto de los alcaldes mayores, sugiriendo además que el paso por corregidurías políticas y de capa y espada podía constituir un camino ascendente hacia una alcaldía mayor ${ }^{17}$.

En Santa Fe del Río de la Plata, el oficio de alcalde mayor fue utilizado por primera vez en 1583 con atribuciones similares -casi idénticas-a las del teniente de gobernador, sin suprimir ni suspender la autoridad de este último. Coexistieron. Juan de Garay, lugarteniente del adelantado del Paraguay y Río de la Plata en cuya calidad fundó al ciudad de Santa Fe en 1573, iba a emprender una campaña contra los indios y antes de hacerlo, sin suspender al teniente de gobernador, extendió el título de alcalde mayor a Antonio Tomás para que "[...] riga y administre y haga Justicia En lo civil y criminal apedimento de parte [...] y podais entrar en Cavildo $y$ hazer el oficio de Justicia mayor y para hablar de indios y determinar los pleytos que sobre ello se rreceviere y para compeler y apremiar a los capitanes caudillos $y$ quadrillas que yo dexo señalados [...]"18. Esta superposición ilustra lo que Alfonso García Gallo afirmaba que sucedía en los territorios americanos de la monarquía hacia los años 1570, cuando y donde los gobernadores y sus delegados podían nombrar tenientes y alcaldes mayores porque así los facultaba el título ${ }^{19}$ que a ellos había sido extendido. Lo que el jurista señalaba es que aunque el oficio de alcalde

${ }^{16}$ EsCriCHE, Joaquín de, Diccionario razonado de legislación y jurisprudencia (Nueva edición corregida notablemente y aumentada con nuevos artículos, notas y adiciones sobre el derecho americano por don Juan B. Guim, doctor en ambos derechos y abogado de los tribunales de España, París, Librería de Rosa, 1851), p. 129.

${ }^{17}$ EsCRICHE, Joaquín, [Diccionario, cit. ](n. 16), p. 162.

${ }^{18}$ AGSF, "Actas de Cabildo", I, ff. 51-52.

${ }^{19}$ Juan de Garay obró como lugarteniente de adelantado. No era jurista, pero tenía experiencia como regidor en Santa Cruz de la Sierra y su cercanía con las autoridades del cabildo de Asunción le habían permitido conocer el uso de esta figura. En Asunción se había implementado -aunque con otras características, puesto que era sede de Gobernación- en el primer cabildo (1541). Museo Mitre, “Archivo colonial”, Arm. B, C. 13, 28; otro nombramiento (de 1596) en Actas capitulares del cabildo de Asunción del Paraguay, f. 46, disponible en www.bvp.org.py 
mayor era esencialmente judicial, ocasionalmente y por necesidad se extendió concediéndoles funciones de gobierno y que esto es lo que condujo a equipararlos $\mathrm{y}$, a veces a confundirlos, con los corregidores. ${ }^{20}$ En contraste con lo que sugería y mandaba la normativa para el oficio de alcalde mayor en la Península, el de Santa Fe-que como vimos era una figura de justicia y gobierno delegada a su vez por un lugarteniente- fue lego y no letrado. Para Óscar Cruz Barney, el mismo tipo de confusión -entre alcaldes mayores y tenientes de gobernador- apareció en Nueva España, aunque da por zanjado el problema hacia 1536. Este autor, aunque en otros casos generaliza, sobre esto marcó perfectamente el diferente impacto regional de "la institución de los alcaldes mayores [que] se generaliza y arraiga en la Nueva España, no así en el Perú. Existían, además, los alcaldes mayores de audiencia a imitación de los alcaldes mayores del reino, surgidos en España, específicamente en Galicia”21.

El uso del oficio de alcalde mayor no se extendió por mucho tiempo en Santa Fe: a comienzos de 1584, Antonio Tomás (nombrado alcalde mayor en 1583) fue designado teniente de gobernador interino y cuando dicho cargo fue asumido en calidad de titular por Gonzalo Martel de Guzmán, la alcaldía mayor no le fue restituida. Su efímera presencia en el cabildo santafesino se dio por concluida ${ }^{22}$.

El oficio de corregidor, a pesar de ser conocido, no se utilizó en Santa Fe durante el siglo XVI, como sí se implementó en el Perú de las Leyes Nuevas.

No obstante admitir las confusiones existentes, Guillermo Lohmann Villena estudió a fondo los términos de la discusión coetánea sobre el nombre que debía darse, por ejemplo, al recientemente creado oficio de corregidor de indios y llegó a la conclusión de que, al menos en el Perú de los Austrias, la distinción se hizo nítida. Examinó los proyectos y mostró los caminos por donde discurrió la disquisición acerca de cuál era el mejor modo de designar el nuevo tipo de funcionario que iban a poner al frente de un también nuevo distrito territorial: el licenciado García de Castro tenía claro que el título de la autoridad que estaba creando no respondía "[...] a simples diferencias nominales, sino que afecta muchas veces a la propia sustancia constitutiva de tales magistraturas. [...] García de Castro las apellidó desde un principio con su título castizo [corregidores] por estimar que el apelativo de alcaldes mayores correspondía a las autoridades propias de los lugares de señorío [...]"23.

${ }^{20}$ Solórzano, cuya pericia sobre los asuntos del gobierno indiano nunca fue puesta en duda, llegó a decir que, en América, se trataba del mismo oficio con distinto nombre. Esta fusión es de máxima frecuencia cuando se trata de "corregidores" y de "alcaldes mayores" de indios y sobre todo en el Perú: de despejarlas se ocupa el prolijo estudio de LoHmann ViLLENA, Guillermo, El corregidor de indios en el Perú bajo los Austrias (Lima, Pontificia Universidad Católica del Perú, 2001).

${ }^{21}$ Cruz Barney, Óscar, Derecho, cit. (n. 2), p. 101

${ }^{22}$ AGSF, AC, Tomo I, sesiones de enero a abril de 1583. La figura reaparece en el siglo XIX para reemplazar a los alcaldes de la hermandad y antes de la instrumentación de los juzgados de paz en la villa del Rosario. BARRIERA, Darío G., La organización del territorio y su gobierno: alcaldes mayores para la villa del Rosario. Un capitulo de transición (1826-1832), en Revista de la Junta Provincial de Estudios Históricos de Santa Fe, 70 (Santa Fe, 2012).

${ }^{23}$ Lohmann Villena, Guillermo, El corregidor, cit. (n. 20), pp. 86-87. 


\section{Gobernados por corregidores (SAnta Fe, 1663-1673)}

El 3 de julio de 1673, los oficiales de la Real Hacienda de Buenos Aires ordenaron al cabildo de Santa Fe que la tasación de la media anata ${ }^{24}$ para el cargo de teniente de gobernador la formulara el capitán Bartolomé Márquez (tesorero de la ciudad). No podían fijar la suma que debía enterar Antonio de Godoy, el nuevo teniente de la ciudad ${ }^{25}$, porque -afirmaron- no encontraban en su juzgado un ejemplar precedente "de lo que se debe del derecho de la media Anatta por los thenientes de la ciudad de santa fe respecto que de de dies años a esta parte an sido corregidores y lugartenientes [...]"26. El nuevo teniente integró 430 pesos de a 8 reales. La cita permite refrendar el periodo durante el cual en la ciudad no habían tenido sede los consabidos tenientes de gobernador -que presidieran el cabildo desde su fundación en 1573- sino un corregidor tanto como cierta simulación en la desmemoria, dado que hasta 1663 el cabildo había sido presidido, durante noventa años, por tenientes de gobernador designados desde Asunción primero (hasta 1617) y desde Buenos Aires después (dese 1618) ${ }^{27}$.

El primero en presentar el título de corregidor en la ciudad de Santa Fe fue el capitán Diego Tomás de Santuchos, vecino encomendero, descendiente directo del primer alcalde mayor de la ciudad, don Antonio Tomás. El título, librado por el gobernador de Buenos Aires y presidente de su flamante Real Audiencia, José Martínez de Salazar, lo instituía como "corregidor, mi lugar teniente y capitán a guerra de la ciudad de Santa Fe y su jurisdicción [...]"28. En él, afirmaba la autoridad que lo designaba, confluían una historia de Real Servicio -listó entre sus méritos que se había desempeñado en varias ocasiones como alcalde de primer voto y además haber colaborado activamente en la mudanza de la ciudad durante la década de

${ }^{24}$ Covarrubias, Tesoro, cit. (n. 13), p. 134 escribió: "media anata vale los medios frutos de un año". Se trata de un derecho pecuniario a favor de la Real Hacienda que debían integrar todos los "empleos" que generaran sueldos salvo excepciones expresas y explícitas. La "media anata”, desde 1631, tributaba un porcentaje variable-según la sede-sobre la renta de medio año para todos los oficios, incluidos los Grandes, Títulos y Barones; fue suprimida definitivamente entre 1845 y 1848 . La annata eclesiástica era pagada por los beneficios mayores (arzobispados, episcopados) y la media por los menores. Fue instalada por primera vez por Juan XXII (segundo pontífice con sede en Avignon, 1316-1334) y condenada luego por el concilio de Basilea (1431-1455). Martínez Alcubilla, Marcelo Diccionario de administración (Madrid, imprenta propia, 1858), p. 155.

${ }^{25}$ El título expedido fue el de "theniente de gobernador, justicia mayor desta ciudad y capitán a guerra en ella despachado por el Señor mestre de campo D. Joseph Martinez de Salassar Cavallero de la orden de Santiago Governador y Capitán general desta provincia [...]”, AGSF, AC, VI, f. 311. 1 de Agosto de 1673. Godoy había sido teniente general del Tucumán durante la gobernación de Mercado y Villacorta.

${ }^{26}$ AGSF, AC, VI, f. 315.

${ }^{27}$ Poco después, Felipe IV estableció que el distrito de la Audiencia de Charcas fuera gobernado por cuatro gobernadores (los de Santa Cruz de la Sierra y Río de la Plata como capitanes generales; los de Tucumán y Paraguay solo como gobernadores), tres corregidores (los de Potosí, Oruro y Chuquiago) y un alcalde mayor de minas (el de Potosí). Sumarios, libro IV, título $4^{\circ}$, ley $2^{\mathrm{a}}$.

${ }^{28}$ AGSF, AC, IV, f. 146, copia del título en las actas de la sesión del 6 de octubre de 1663. Su fiador fue Diego de Vega y Frías. 
1650 - constando que en todas las ocasiones se habían desempeñado "aventajadamente" y su superior aseguraba confiar en que "continuará en adelante asistiendo al Real servicio y buena administración de justicia en el nombre de su Magestad".

El nombramiento se realizó "[...] por el término de un año o más, según mi voluntad [...]" y se le señalaron como atributos visibles de su autoridad "[...] bara alta de justicia en lo que toca a su administración y en la de cappn a guerra con Insignia militar en todos los casos que se ofresieren [...]"29.

La designación subrayaba claramente la dependencia directa del corregidor de su superior -el gobernador y presidente de la Audiencia pretorial de Buenos Aires (la presidía un gobernador que no dependía de un virrey sino que tomaba directamente contacto con el Rey y el Consejo de Indias) $)^{30}$ y la continuidad con las potestades del anterior oficio para la función, el teniente de gobernador -vara alta de justicia (lo posiciona como justicia mayor en la ciudad) e "insignia", símbolo de su jefatura o mando sobre las fuerzas militares con asiento en la ciudad y su jurisdicción.

Diego Tomás de Santuchos usufructuó del título algo más de un año. El 23 de julio de 1665, el capitán Juan Zacarías de la Sierra Morales presentó ante el cabildo su título de "corregidor, justicia mayor y capitán a guerra de Santa Fe", extendido por la misma autoridad ${ }^{31}$. Los posteriores fueron Antonio de Vera Mujica ${ }^{32}$ y Hernando Rivera de Mondragón -este último vecino de Buenos Aires. Sierra Morales ejerció también como juez de bienes de difuntos ${ }^{33}$ y terció a favor del escribano de residencia Tomás de Salas, cuestionado en la ciudad por tener una causa criminal pendiente en la de Buenos Aires. Curiosamente, y en la misma sesión, el regidor propietario Antonio Suárez Altamirano renunció a su silla sin venderla - "hace dejación del dho oficio de regidor y lo pone en manos de su magestad" - a causa del "gran gasto" que le ocasiona ser residenciado cada dos años ${ }^{34}$, todo lo cual mueve a tomar seriamente las actividades de los residenciadores (entre los cuales figuraban los propios corregidores o tenientes que, en ocasiones, faltaban al cabildo por estar ocupados en "negocios de residencia").

Las tareas cumplidas por los corregidores, esto es, las atribuciones que se

${ }^{29}$ AGSF, AC, IV, f. 146 v.

${ }^{30}$ Según la Real Cédula del 6 de abril de 1661, al frente de la Audiencia se colocó un presidente "de capa y espada", elegido por su capacidad militar y, además, conforme al principal objetivo que se perseguía, cual era el de combatir el contrabando y frenar los avances de otras monarquías sobre el Plata. Este presidente-gobernador se jerarquizó frente a los gobernadores del Tucumán y del Paraguay. Sobre los límites de la independencia de la Audiencia respecto del virrey del Perú véase CauzzI, Teresa, Historia de la primera Audiencia de Buenos Aires (16611672) (Rosario, Universidad Católica Argentina, 1984), p. 142 ss.

${ }^{31}$ Sus fiadores fueron el sargento mayor Miguel Martín de la Rosa y Pablo Arvestain, AGSF, AC, Tomo IV, ff. 206v-207.

${ }^{32}$ Quien en 1666 había sido designado por el cabildo como apoderado de la ciudad ante la Real Audiencia, AGSF, AC, IV, f. 233. Su casa ofició de sede del cabildo durante parte del periodo que duraron las obras en 1669. AGSF, carp. 7, legajo 7, f. 52.

${ }^{33}$ AGSF, AC, IV, f. 209.

${ }^{34} \mathrm{AGSF}, \mathrm{AC}$, IV, f. 211 v. La exclusión se concretó varios meses después, el 5 de mayo de 1666. 
deducen del trabajo y las obligaciones que lo afectaron efectivamente durante los años en que se ejerció el oficio, no difirieron de las que habían desempeñado los tenientes de gobernador: cada corregidor integró su media anata ${ }^{35}$, presidió el cabildo, aprobó las elecciones, terció en las empatadas, presentó cédulas reales, ordenó la publicación de los autos de buen gobierno, ejecutó la Bula de la Santa Cruzada, tomó cuentas de la alcabala al alcalde de primer voto, dirimió empates en votaciones para asignar pulperías, designó a quienes debían controlar las pulperías de realengo, en fin, tareas de gobierno al frente del cabildo como las realizadas por el teniente de gobernador ${ }^{36}$.

La práctica se condice perfectamente con la normativa regia: todo parece indicar un reemplazo de funciones con un cambio de nombres promovido por la creación de la Real Audiencia de Buenos Aires. Esto demuestra que los tenientes de gobernador se comportaron en Santa Fe como lo hacían los corregidores respecto de sus superiores en los territorios donde tempranamente hubo Reales Audiencias como organismos de gobierno y justicia. En efecto, el reemplazo de los tenientes por corregidores en Santa Fe es el correlato de los cambios institucionales en lo que concierne a la subdivisión judicial del virreinato del Perú: el periodo durante el cual Santa Fe fue sede de corregidor $^{37}$ se corresponde con el de la creación y funcionamiento de la Primera Real Audiencia de Buenos Aires ${ }^{38}$.

Sin embargo, en la teoría y en la práctica jursdiccionalista, los territorios de las Audiencias podían dividirse en corregimientos pero no necesariamente debían hacerlo. El caso rioplatense muestra que la temprana práctica de la organización diocesana $^{39}$-en gobernaciones- era difícil de modificar: las gobernaciones no se transformaban en corregimientos de la noche a la mañana. Aunque pasó a ser sede de un corregidor, la ciudad de Santa Fe siguió siendo sufragánea de la gobernación de Buenos Aires sin transformarse en cabecera de corregimiento. La mutación del título de teniente de gobernador en el de corregidor prolongaba así la reunión de las atribuciones de justicia mayor, jefatura de guerra y capacidad de presidir el cabildo en representación del gobernador, que sumaba entonces la condición de ser el gobernador-presidente de la primera Real Audiencia de Buenos Aires ${ }^{40}$.

\footnotetext{
${ }^{35}$ Que fue de 50 pesos corrientes. Copia de las actuaciones en la sesión del 28 de noviembre de 1664, AGSF, AC, IV, ff. 180-189.

${ }^{36}$ AGSF, AC, IV, passim.

${ }^{37}$ En 1624 se designaron otro tipo de corregidores -corregidores para las reducciones de indios, concretamente, de los calchines y de los chanáes. Fue por muy poco tiempo. Sucedió lo mismo en Corrientes, ver SALINAS, María Laura, Encomienda, trabajo y servidumbre indígena en Corrientes. Siglos XVII-XVIII (Tesis de Maestría, Universidad Internacional de Andalucía, La Rábida, 2008).

${ }^{38}$ Sobre la cual el estudio más completo sigue siendo el ya citado de Teresa Cauzzi.

${ }^{39}$ Utilizo esta expresión en su sentido laico y etimológico, como la conjunción de dioikesis (gobierno y administración). Cfr. Monlau, Pedro Felipe Diccionario etimológico de la lengua castellana (Madrid, Imprenta de Rivadeneyra, 1856). Por su parte y más recientemente, Joan Corominas señaló la relación entre esta raíz y la palabra del latín tardío diocesis (circunscripción) y confirmó que la utilización del adjetivo (diocesano) data de mucho antes de su utilización tardo-medieval, vinculada con la organización eclesiástica. CoROMINAS, Joan, Diccionario crítico etimológico castellano e hispánico (Madrid, Gredos, 1984), II, p. 498.

${ }^{40}$ En este sentido podrían haberse considerado, como lo hace Pazos para Nueva España,
} 
El 31 de octubre de 1672, el gobernador José Martínez de Salazar comunicó al cabildo santafesino, a través de una nota, la extinción de la Real Audiencia de Buenos Aires, y les comunicó que la ciudad volvía a quedar bajo la jurisdicción de la de La Plata. Para que fuera "más notorio al común desta ciudad", el cuerpo decide publicarla como bando en la plaza, a toque de caja de guerra-modalidad utilizada para noticias importantes ${ }^{41}$.

La expresión patente del cambio se confirmó en el momento de la extinción del oficio, cuya fragilidad corrió de la mano de la misma condición por parte de la mencionada primera Real Audiencia: el último corregidor de gobierno nombrado por la Real Audiencia de Buenos Aires (Hernando Rivera de Mondragón) presentó ante el cabildo santafesino dos títulos diferentes: el 24 de enero de 1673 uno de corregidor y capitán a guerra de Santa Fe otorgado por José Martínez de Salazar en calidad de gobernador y presidente de la mencionada Real Audiencia -donde además se aclaraba que como tal gozaba de las mismas atribuciones que los corregidores de Chile $-{ }^{42}$ y el 9 de febrero del mismo año otro de teniente de gobernador, justicia mayor y capitán a guerra de la ciudad también extendido por Martínez de Salazar, pero ya no en calidad de presidente de la Real Audiencia de Buenos Aires sino de gobernador y, por lo tanto, ahora el título se extendía nuevamente, como hasta 1663, ad referendum de la aprobación de la Real Audiencia de La Plata ${ }^{43}$.

A partir de entonces, el teniente recuperó la condición explícita de justicia mayor (algo que de todos modos como corregidor también detentaba) pero quedó nuevamente en una posición incómoda frente al cabildo -como a comienzos del siglo XVII, se vio nuevamente fortalecido con este instrumento- , puesto que a diferencia del corregidor, que no necesitaba aprobación de una Real Audiencia porque había sido designado por ella, su aceptación por el cuerpo local quedaba supeditada a una decisión que podía resultar una molestia para el teniente ${ }^{44}$ haciéndole esperar su confirmación por la-ahora nuevamente lejana- Real Audiencia de los Charcas en la ciudad de La Plata, en el Alto Perú.

La resignificación del teniente como corregidor fue posible sin travestir la organización interna de la antigua provincia con categorías territoriales de Real Audiencia: en Santa Fe del Río de la Plata hubo corregidor pero la Provincia no

como una injerencia del poder monárquico en la ciudad. Sin embargo se ha visto que no es así. No se trata de una "implantación" de un "poder central” en el municipio, sino de un lugarteniente del gobernador que, ahora, era el Presidente de la Audiencia -por lo cual no dejaba de constituir parte de la constelación de poderes "locales”. Cfr. PAZOs, María Luisa, El Ayuntamiento de la ciudad de México en el siglo XVII. Continuidad institucional y cambio social (Diputación de Sevilla, Sevilla, 1999).

${ }^{41}$ AGSF, AC, IV, f. 294 v, 25 de noviembre de 1672. No obstante el comunicado, la primera elección de 1673 fue todavía regulada y aprobada por el corregidor.

${ }^{42}$ AGSF, AC, IV, ff. 301-303.

${ }^{43}$ AGSF, AC, IV, ff. 303v-304.

${ }^{44}$ Como sucedió en reiteradas ocasiones durante el siglo XVII. Cfr. BARRIERA, Darío, Resistir al Teniente con la letra del Rey: la conflictiva relación del Cabildo de Santa Fe con la Gobernación del Río de la Plata, años 1620, en Dalla CoRTe, Gabriela y otros (coordinadores), X Encuentro Debate "América Latina Ayer y Hoy: homogeneidad, diferencia y exclusión en América" (Barcelona, Universidad de Barcelona, 2006), pp. 65-72. 
se reorganizó en corregimientos, la ciudad no devino sede de corregimiento. Así, el artificio institucional de la provincia menor de tipo antiguo subsistió y convivió con la erección de la Real Audiencia de Buenos Aires sin que el territorio de dicha gobernación, como correspondía de realizar la transformación a rajatabla, fuera dividido en corregimientos a cuyo cargo estarían los corregidores. El corregidor santafesino, comportándose como un teniente de gobernador, se asemejó al castellano en tanto que "[...] emisario de la corona para ejercer el gobierno y la justicia en las ciudades [...] magistrado mediante el cual pretendían contrarrestar las aspiraciones localistas de los núcleos urbanos" ${ }^{35}$.

El oficio -no la función, que antes y después fue la de teniente de gobernador y un siglo más tarde, cumplida también por el borbónico subdelegado de guerra y hacienda- desapareció del lenguaje político de los santafesinos desde el cese del último corregidor en 1673. Tampoco despareció la palabra, desde luego, pero nunca volvió a formar parte del lenguaje para comprender o explicar la constelación local de oficios o territorios: en 1699 un corregidor de Andalguailas fue comisionado para obtener un dinero de la ciudad en Charcas ${ }^{46}$ y en 1718 se recibieron y acataron dos cédulas reales del año anterior que conminaban a los cabildos a no impedir la recepción de gobernadores-corregidores $y$ demás ministros ${ }^{47}$. Vuelve a aparecer en la pluma del escribano cuando transcribe la orden de la Real Audiencia de La Plata de dar a conocer un auto provisto a instancias del fiscal, ordenando su publicación a "gobernadores y corregidores"; lo mismo -que el oficio aparece mencionado en papeles de la Real Audiencia- ocurre en 1767 y en 1785, cuando se circula precisamente el contenido de la Real Ordenanza de Intendentes de 1782 y el cuerpo, ante el cese de gobernadores y corregidores que disponen los capítulos $7^{\circ}$ y $8^{\circ}$, se pregunta si debe cesar en su cargo el teniente de gobernador -que no es nombrado pero se colige, por la supresión de su superior- $y$, en caso positivo, en quién "recaerá el mando político" de la ciudad ${ }^{48}$.

\section{Las Reformas: Santa Fe bajo la Segunda Real Audiencia de Buenos Aires}

En efecto, dicha supresión o "cese" de los corregidores no afectaba ya a Santa $\mathrm{Fe}$, que no había sido sede de un "corregimiento" al estilo peninsular ni al estilo peruano. El oficio tampoco tuvo la tradición de gubernamentalidad que tuvo en Chile o Cuyo, donde fungieron tempranamente como cabeza de los cabildos locales.

El cabildo de la ciudad de Santa Fe, al contrario que los de Mendoza, Santiago o Cuzco ${ }^{49}$, por citar unos pocos ejemplos, fue presidido por tenientes de adelantado

\footnotetext{
${ }^{45}$ ZORRAQUín BECÚ, Ricardo, La organización política argentina en el periodo hispánico (1959,

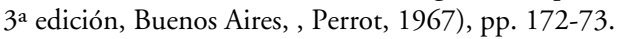

${ }^{46}$ AGSF, AC, VI, f. 194.

${ }^{47}$ AGSF, AC, VIII, f. 13v

${ }^{48}$ AGSF, AC, XV, ff. 156-159, sesión del 24 de octubre de 1785.

${ }^{49}$ Sobre el corregidor y sus funciones en estas áreas remito a los clásicos estudios de Enrique Ruiz Guiñazú, Edberto Oscar Acevedo y, muy recientemente, el de Inés Sanjurjo, que
} 
(de los adelantados del Paraguay hasta 1593), de los tenientes de gobernador del Paraguay y Río de la Plata (entre 1593 y 1617), de los tenientes de gobernador de Buenos Aires (o del Río de la Plata, era indistinto, desde 1618) y, salvo ese interludio señalado entre 1663 y 1673, hasta la sesión del 24 de octubre de 1785, cuando habían pasado más de cuarenta meses de la entrada en vigor de los distintos capítulos de la Real Ordenanza de Intendentes, seguía siendo presidido por un teniente de gobernador de Buenos Aires.

Todo esto no significó nunca una anomalía: bien al contrario, como se dijo, durante el periodo en que funcionó la primera Audiencia de Buenos Aires, y aunque de hecho la práctica siguió siendo esencialmente la misma, la máxima autoridad de justicia y gobierno pasó a ser un corregidor que, como tal, era designado por el gobernador pero en su calidad de presidente de la Audiencia.

A pesar de la cercanía física de Santa Fe con otras regiones donde la institución del corregimiento funcionó desde épocas muy tempranas -es el caso de las ya mencionadas provincia de Cuyo, reino y capitanía de Chile o provincias centrales del virreinato del Perú- la práctica institucional, esto es, las creaciones instituyentes de los agentes que hicieron el gobierno de la monarquía en el Río de la Plata, no lo incluyó entre sus renglones a causa del modelo diocesano: si bien los súbditos de las gobernaciones del Paraguay y del Río de la Plata estuvieron subordinadas por ejemplo a la Real Audiencia de Charcas mientras no existió la de Buenos Aires, dicho organismo, del mismo modo que no lo consiguió el virrey del Perú durante la década de 1570, nunca incidió creando espacios institucionales dentro de las gobernaciones, aunque -desde luego generando conflictos- no hubiera sido imposible.

La cabecera de la gobernación rioplatense, transformada en sede de la Intendencia -y luego incluso en Intendencia central- de Buenos Aires, volvió a convertirse en sede de una Real Audiencia a partir de 1785. Sin embargo, este cambio tampoco modificó la división territorial de la gobernación a favor del modelo de las Audiencias porque, precisamente, las reformas propugnaban la instalación de un modelo que venía a cuestionarlo y reemplazarlo, cesando a los corregidores y gobernadores donde los hubiera, y nombrando al frente de las ciudades subdelegados de Guerra y Hacienda, que como su nombre mismo lo indica no concentraba las cuatro causas y formaba parte de un modelo de gobierno más complejo que, en el nivel municipal, distribuía funciones y responsabilidades que ejercían mutuas relaciones de vigilancia.

\section{Corregidores DE INDIOS E INDIOS CORREGIDORES}

Aunque en la región tampoco hubo corregimientos de indios, la figura de los corregidores de indios y de los corregidores indígenas tuvieron más larga vida. $\mathrm{Su}$

sintetiza muy bien los mismos y avanza examinando el perfil social de los corregidores de Cuyo y sus conflictos con el cabildo mendocino. Véase SANJuRJo, Iné, Los corregidores de la Provincia de Cuyo y sus agitadas relaciones con el cabildo de Mendoza (1748-1784), en RicHarD-JorbA, Rodolfo - Marta S. BonAUdo (coordinadores), Historia Regional. Enfoques y articulaciones para complejizar una historia nacional (La Plata, EdUNLP, 2014), pp. 37-52. 
estudio queda abierto para más adelante, pero a los efectos de esta presentación es preciso al menos señalar su existencia y su lugar en el esquema jurisdiccional, aunque por el momento este escaso desarrollo no permita devengar más rédito que el que surja de impedir su oclusión en el panorama que se presenta.

\section{Una efimera experiencia (siglo XVII).}

Aunque no faltaron situaciones donde se entablaron relaciones amistosas y hasta se dieron algunas alianzas, durante el proceso de invasión, conquista y colonización de los pueblos americanos, los invasores europeos claramente subordinaron a los nativos bajo formas jurídica y físicamente diferentes. En el marco de una guerra planteada por el europeo como justa, los nativos fueron diferencial -y no consecutiva ni homogéneamente- eliminados físicamente, esclavizados, cristianizados, encomendados, convertidos en súbditos, relocalizados y siempre subordinados a un esquema económico, social y político que en todos los casos les resultó radicalmente otro. Asignados individualmente como yanaconas afectados a servicios personales ${ }^{50} \mathrm{o}$, a través de la modalidad más frecuente en encomiendas -sujetos a un vínculo que los obligaba a trabajos diversos para satisfacer tributos o cargas impuestas a su encomendero-, los nativos conquistados fueron además objeto de una política de occidentalización y cristianización de sus patrones de asentamiento que supuso, sobre todo, reducirlos a vivir en pueblos ${ }^{51}$.

La Corona los implementó de manera estratégica y a escala continental a partir de los años 1550. Podían haber sido antes objeto de encomienda y, sin importar o no si tenían un cura doctrinero asignado -recuérdese que entre las obligaciones del encomendero figuraba en primer lugar la de cristianizar a sus encomendados ${ }^{52}$ se movilizaba y organizaba a los nativos para vivir en católica policía. Aunque casi siempre en asociación con otros agentes, esta relocalización y espacialización forzosa de familias o grupos enteros de indios se daba en los términos del cabildo de alguna ciudad hispánica, de donde emanaba la jurisdicción -y por eso, la capacidad delegada para administrar justicia.

En el virreinato del Perú, el corregimiento de indios y su titular, el corregidor, fueron creados en $1565^{53}$. El contexto es importante: acababa de librarse una fuerte disputa entre juristas y mentores del gobierno metropolitano y los agentes locales de la primera hora de la conquista en torno a la perpetuidad de las encomiendas y esto abría el panorama sobre el gobierno colonial cara a cara de las comunidades encomendadas. Una clara negativa de la Corona a la propuesta de otorgar jurisdicción sobre los indígenas a los encomenderos abrió las puertas para este

\footnotetext{
${ }^{50}$ Aunque no tan extendida como en el área andina, de donde proviene la categoría, se utilizó ocasionalmente para nombrar a indios asignados a servicios personales de algún vecino feudatario en su casa solariega en la ciudad. P. ej. Diego, el indio que asumió como pregonero en noviembre de 1584, nombrado como yanacona de Juan de Vallejo. ACSF, AC, I, f. 84 v.

${ }^{51}$ GeHrard, Peter, Geografía histórica de la Nueva España, 1519-1821 (México, Universidad Nacional Autónoma de México, 1986), "Introducción”.

${ }^{52}$ Zavala, Silvio, La encomienda indiana (México, Editorial Porrúa, 1973).

${ }^{53}$ Esto a pesar de que existe una Real Cédula de Carlos V del 8 de noviembre de 1550 . Sumarios, libro IV, título $4^{\circ}$, ley $23^{\mathrm{a}}$.
} 
proyecto: privados los corregidores de las ciudades de administrar justicia sobre los pueblos de indios, y habiendo revertido el feudo de los indios encomendados a la Corona como consecuencia de las "Leyes Nuevas" 54 , el licenciado Lope García de Castro, miembro del Consejo de Indias desde 1558, planteó la creación de los corregimientos de indios que tendrían a su frente a corregidores de indios, quienes reunirían las funciones de gobierno, justicia y recaudación de tributos. ${ }^{55}$ Como ha señalado C. S. Assadourian, los corregidores de indios constituyeron una de las instituciones típicas de la disputa por el poder político entre la Corona, los conquistadores, las ciudades y los jefes nativos en el periodo que él denomina de la transición y-siguiendo el testimonio del licenciado Falcón (1583) - notó que bien pronto se convirtieron en "[...] empresarios y movilizadores de la energía campesina”, enriqueciéndose rápida y en muchos casos inescrupulosamente $e^{56}$. A causa de los abusos y excesos cometidos, muchos corregimientos de indios fueron suprimidos a lo largo del siglo XVII atendiéndose particularmente las formas de reorganización que esto implicó en cada caso.

Para las provincias del Paraguay y el Río de la Plata, la normativa que mandaba que todos los indígenas encomendados vivieran reducidos en pueblos data de finales de 1611. La institucionalización de las aldeas indígenas bajo el régimen de encomiendas como pueblos de indios -así como también “[...] el respeto por las autoridades indígenas tradicionales y la designación de alcaldes, además del reemplazo del servicio personal por un tributo [...]" ${ }^{57}$ - fueron algunas de las principales medidas impulsadas por Francisco de Alfaro, oidor de la Real Audiencia de Charcas, a través de sus ordenanzas (del 11 de octubre de 1611) tendientes a organizar la formas de sujeción y explotación existentes tanto como a evitar la corresidencia con los indígenas (especialmente la cohabitación con sus mujeres) de "ningun español ni mestizo negro ni mulato" 58 .

Sobre estos pueblos no podía tener jurisdicción el alcalde de la hermandad y el gobierno de estos pueblos debía hacerse por medio de sus propios alcaldes mientras que el repartimiento de los indios para la mita quedaba a cargo del ca-

${ }^{54}$ Simpson, Lesley Byrd, The "encomienda" in New Spain. The Beginning of Spanish Mexico (Berkeley, University of California Press, 1966).

${ }^{55}$ Estas razones, sumadas a otras coyunturales - se aprovechó la muerte de varios corregidores urbanos para eliminar la institución de ciudades donde había alcaldes ordinarios, como Piura, Lima, Huamanga, Huánuco y Chachapoyas- favorecieron el proyecto de García de Castro de implantar los corregimientos de indios en las regiones centrales del virreinato peruano. LOHMANN VILLENA, Guillermo, El corregidor, cit. (n. 20), pp. 70-74.

${ }^{56}$ Assadourian, Carlos, El sistema de la economía colonial (Lima, IEP, 1982), p. 306.

${ }^{57}$ Farberman, Judith Santiago del Estero y sus pueblos de indios. De las ordenanzas de Alfaro (1612) a las guerras de Independencia, en Andes, 19 (Salta, 2008), pp. 225-250. Sobre el servicio personal, LORANDI, Ana María, El servicio personal como agente de desestructuración en el Tucumán colonial, en Revista Andina, 6 (Cuzco, 1988). El trabajo de Farberman (así como los anteriores que realizó con Boixadós) muestra bien que las ordenanzas de Alfaro fueron muy resistidas y que la realidad territorial fue bastante diversa incluso dentro de una misma jurisdicción.

${ }^{58}$ Extracto de las Ordenanzas hechas por el licenciado don Francisco de Alfaro, oidor de la Audiencia de los Charcas, para uso de la gobernación del Paraguay y Río de la Plata con los decretos del Consejo de Indias, 11 de octubre de 1611, Biblioteca Nacional, "Colección Gaspar García Viñas", CXCII, BN 4123. 
cique (ordenanza 50a , título del modo de gobierno). La intención de este cuerpo normativo era que cada pueblo de indios tuviera uno o más alcaldes y -según su extensión- regidores cadañeros, supeditados a un justicia mayor residente en el cabildo de la ciudad a la cual perteneciese su jurisdicción, pero explícitamente inhibido de residir - del mismo modo que el encomendero, quien no podía pasar allí más de una noche- en el pueblo mismo. De este modo, había una preocupación explícita para que no hubiera en estos pueblos "pobleros ni administradores ni mayordomos" (ord. 13 ) y que no se nombren corregidores (ord. 51 a), quedando a cargo de los justicia mayor y alcaldes ordinarios de las ciudades españolas el cobro de las mitas ${ }^{59}$.

Las ordenanzas fueron recibidas y confirmadas en Santa Fe en 1618, pero las prohibiciones vigentes no parecen haber constituido un obstáculo para el cabildo santafesino en 1624: ese año, el cuerpo nombró corregidor de la reducción de los calchines a Pedro de Oliver y a Pero Gómez corregidor de la reducción de los chanáes ${ }^{60}$. La experiencia se cerró al poco tiempo a partir de un dispositivo corriente que ya hemos estudiado para la regulación de otras trasgresiones normativas: el regidor Pedro Ruiz de Villegas presentó al cabildo una petición intimando el cumplimiento de varias piezas normativas, entre las cuales figuraba una Real Cédula del 28 de diciembre de $1619^{61}$ que prohibía la designación de parientes y allegados en cargos de mando (esto cuestionaba la legitimidad de Juan de Zamudio como teniente de gobernador de Santa Fe) y una Real Provisión de la Real Audiencia de La Plata que refrendaba las ordenanzas de Francisco de Alfaro $^{62}$. En lo que concierne a esta última, el regidor citaba particularmente el capítulo que ordenaba la cesación de pobleros y administradores de los pueblos de indios ${ }^{63}$. Los corregidores fueron separados de sus efímeros cargos y sobre el final del mismo año, el cabildo santafesino transcribió, a petición de un vecino, una Real Provisión sobre repartimiento de indios dada para Santa Fe por la misma Audiencia, donde mandaba la prestación de servicios de los indios en sementeras y construcción de casas estuviera bajo el cuidado del cabildo, enfatizando que no se los sacara a las vaquerías ${ }^{64}$.

En Corrientes, ciudad bajo la misma jurisdicción civil y eclesiástica que Santa $\mathrm{Fe}$, hay testimonios de 1653 sobre un corregidor blanco como administrador del pueblo de indios de Santa Lucía. El testimonio aparece en la visita de Garabito de León y se menciona que lo habría designado el gobernador Jacinto de Lariz ${ }^{65}$ pero cartas del gobernador Dávila dan cuentas de que los indios -aliados con los padres de la Compañía y aferrados a las Ordenanzas de Alfaro como instrumento

\footnotetext{
${ }^{59}$ Extracto de las Ordenanzas, cit.

${ }^{60}$ AGSF, AC, II, f. 158.

${ }^{61}$ Que reiteraba el contenido de otras anteriores, por ejemplo otra dada en Madrid el 16 de diciembre de 1606 .

${ }^{62}$ ACSF, AC, II, f. 285 v. Sesión del 2 de enero de 1627.

${ }^{63}$ Se refería a la decimotercera ordenanza, que mandaba "[...] que no aya pobleros ni administradores ni mayordomos en los pueblos de las encomiendas [...]"

${ }^{64}$ ACSF, AC, II, ff. 318-321, sesión del 12 de octubre de 1627.

${ }^{65}$ Salinas, María Laura, Encomienda, cit. (n. 37), pp. 26 y 123.
} 
de argumentación jurídica- dieron batalla por impedir la designación de corregidores blancos al frente de sus pueblos desde los años $1630 .{ }^{66}$

La figura del corregidor de indios no apareció nuevamente en Santa Fe hasta el siglo XVIII cuando lo hizo en su modalidad de corregidor indígena o "cacique corregidor".

\section{Pueblos de indios y corregidores indios durante el siglo XVIII.}

Siguiendo una línea abierta por varios historiadores de las misiones jesuíticas, Sandra Díaz de Zappia sistematizó los oficios que aparecieron en los cabildos eclesiásticos de las reducciones a cargo de esos religiosos entre 1609 y 1767 . En su detallado estudio sobre la participación indígena en el gobierno de las reducciones, destaca la aparición de la figura del corregidor indígena ya en el siglo XVII. Su estudio constituye para este trabajo una guía y un espejo para contrastar-como lo ha hecho ya Miriam Moriconi ${ }^{67}$ - evidencias y particularidades del caso santafesino; es necesario decir, en este punto, que los historiadores del poder político santafesino casi no se han ocupado -o incluso no hemos detectado- el funcionamiento de las autoridades indígenas en clave de cabildos indígenas, tal cual lo ha propuesto con claridad el mencionado estudio de Moriconi.

Carina Lucaioli sostiene que hacia 1734 la frontera norte santafesina presentaba mayor interacción e interdependencia económica entre indígenas e hispano-criollos, creándose así condiciones que "fueron sentando las bases para el diálogo y las negociaciones" entre estos actores ${ }^{68}$. Siguiendo a Dobrizhoffer [1783 en alemán], ubica los primeros acuerdos de paz entre la ciudad de Santa Fe con abipones y mocovíes hacia 1734 .

Entre 1743 y 1765, y en el marco de una verdadera política de fronteras para el Río de la Plata con el propósito de frenar lo que los hispano-criollos vivían como violencia sobre la ciudad, agentes de la gobernación, de la orden ignaciana y de los mismos pueblos indígenas acordaron la fundación de tres pueblos de indios en jurisdicción santafesina: San Francisco Javier y San Pedro (de mocovíes), "fundados el 21 de julio de 1743 y el 9 de febrero de 1765 respectivamente; y San Gerónimo de indios abipones el 1 de octubre de 1748 " 69 .

\footnotetext{
${ }^{66}$ Trujillo, O. Consenso, cit. (n. 9), 315 y ss. Es muy interesante además el testimonio de quien, para desmarcarse del alcance de un juicio de residencia, afirmó nunca haber tenido el título de corregidor sino apenas el de "mero administrador", AGI, "Escribanía”, 894, A, citado por Trujillo, O Consenso, cit. (n. 9), p. 350. El autor demuestra que el argumento (por falaz) no fue óbice para que el sujeto fuera residenciado.

${ }^{67}$ Remito a un fino análisis de las matrículas de 1785: MORICONI, Miriam, Administración borbónica de pueblos de indios en el Río de la Plata. Matrículas de pueblos de Santa Fe (1785), en Prohistoria, 18 (Rosario, 2012), pp. 144-197.

${ }^{68}$ LuCAIOLI, Carina, Abipones en las fronteras del Chaco. Una etnografia histórica sobre el siglo XVIII (Buenos Aires, Sociedad Argentina de Antropología, 2011), p. 99.

${ }^{69}$ Moriconi, Miriam, Administración, cit. (n. 67), p. 145. Lucaioli, por su parte, sostiene que estas reducciones "[...] no fueron resultado de decisiones unilaterales, sino consecuencias labradas a través de distintas formas de interacción entabladas entre los grupos abipones y los sectores hispano-criollos [...]"; LuCAIOLI, Carina, Abipones, cit. (n. 68), p. 105. Ninguna de las autoras formula estos pueblos como imposiciones a grupos derrotados, sino como formas de interacción.
} 
A los efectos de este trabajo se impone enfatizar dos cuestiones: la primera es que en un acto fundacional para el pueblo, el teniente Vera Mujica dio a los indios del pueblo de San Gerónimo del Rey la posesión del terreno del pueblo jure domine vel quasi, es decir, real, corporal y con la totalidad de derechos e implicancias materiales e inmateriales objeto de la cuasiposesión. ${ }^{70}$ El rito incluyó gestos que se realizaban cuando se otorgaban tierras en merced a españoles o criollos ("arrancando hierbas y esparciéndolas por el aire”) ${ }^{71}$. La segunda es que entre las contrapartes asumidas por los beneficios de la reducción y como parte de la organización mixta que suponía la exclusión de la entrada a los pueblos de cualquier otro "blanco" que no fueran los religiosos, los caciques participantes del acuerdo se obligaban a mantener el gobierno de sus familias haciendo algunas concesiones en su forma de concebir la autoridad política. Un ejemplo podía ser la obligación que tomaron de mantener "la seguridad" de las campañas -la cual era definida claramente desde las expectativas de los criollos y como si se tratara del ejercicio de funciones de alcaldes de hermandad.

Ahora bien, estudiando las matrículas que en 1785 se hicieron de los pueblos de San Javier y San Jerónimo del Rey (de mocovíes y abipones respectivamente) así como un importante volumen de fuentes complementarias, Moriconi hizo notar que los caciques de esos pueblos "asumieron los oficios de corregidores y alcaldes" 72 , componiendo formalmente un cabildo indígena. Esto debe subrayarse no solamente porque para el caso local parece presentar, a diferencia de otras regiones $^{73}$, un subregistro, sino porque señala una dimensión del mestizaje que se presta a interpretaciones controversiales.

Respecto del punto que nos interesa, Lucaioli integra "el nombramiento de los líderes como corregidores de los pueblos, la cesión de varas de mando [...]” o el tratamiento de "don" entre el conjunto de expresiones simbólicas orientadas a subyugar a los indígenas en el marco de la empresa colonizadora ${ }^{74}$, mientras que Moriconi invita a pensar en los diferentes niveles de mestizaje que esto representa. Sandra Díaz -siguiendo a Escandón- hizo notar que en los pueblos de las Misiones el indio corregidor no siempre fue cacique "aunque de haber dos candidatos se optaba por el que lo era”, confirmando entonces que tal condición no era excluyente pero sí preferente ${ }^{75}$. Analizando las matrículas de los pueblos santafesinos, Moriconi encontró además datos muy concretos: en el de San Francisco Javier, el cacique-corregidor era apenas uno de los cuatro caciques del pueblo, era el más joven y además documentó su continuidad en el padrón de 1793. Para el caso

${ }^{70}$ AGSF, junio de 1748 -copiada también en una sesión de noviembre.

${ }^{71}$ Auto del 1 de octubre de 1748, citado en LuCAIOLI, Carina, Abipones, cit. (n. 68), p. 117. Quien actuó como procurador de los receptores fue el Padre Diego de Horbegozo.

${ }^{72}$ Moriconi, Miriam, Administración, cit. (n. 67), p. 162.

${ }^{73}$ Cfr. para Jujuy, SiCA, Gabriela, Transformaciones y formas de legitimación en la autoridad de los caciques coloniales de Jujuy. Siglo XVII, en Memoria Americana, 17 (Buenos Aires, 2009), p. 41. Para las reducciones guaraníes, véanse los trabajos de Lía Quarleri y Sandra Díaz de Zappia, entre muchos otros.

${ }^{74}$ LuCAioli, Carina, Abipones, cit. (n. 68), p. 207.

${ }^{75}$ Díaz de ZAPPIA, Sandra, Participación indígena en el gobierno de las reducciones jesuíticas de guaranies, en Revista de Historia del Derecho, 31 (Buenos Aires, 2003), p. 112. 
del corregidor de San Gerónimo, el registro le indica que su familia era la más extensa, incluyendo en ella "maridos e hijos de sus hijas, criadas y cautivas" ${ }^{\text {" }}$. En coincidencia con los criterios para la conformación de los liderazgos señalados por Lucaioli encuentra que el criterio etario no constituye un factor determinante, así como sugiere la firme incidencia de la relación con el padre misionero.

Lo cierto es que, al menos con la documentación que contamos hasta este momento, las menciones de corregidores indígenas no son coetáneas a la creación de los pueblos y sí muy frecuentes a partir de 1779, con lo cual habría que estudiar o tratar de establecer por qué las designaciones aparecen en este momento y no cuarenta años antes.

Estos líderes, por procesos que habría que explicar detalladamente para contrastar con las hipótesis disponibles, devinieron corregidores de sus propios pueblos y también habían adquirido otras técnicas que tienen que ver con la gubernamentabilidad hispánica: se comunicaban por escrito con curas de otros pueblos $^{77}$, presentaban peticiones en calidad de corregidores de su pueblo ante el cabildo, solicitaron informes ${ }^{78}$, enviaron oficios y comunicaciones escritas al virrey $^{79}$, persiguiendo objetivos muy diversos - desde la obtención de abastos hasta la de ayuda para recuperar a miembros que habían huido. En ocasiones el mismo corregidor indígena fue compelido por el cabildo a recuperar a las familias que se habían escapado de su pueblo; a cambio de este compromiso en la tarea, que podría considerarse una suerte de articulación como "funcionario colonial" conseguía no obstante provisiones indispensables para los suyos en tiempos que a veces eran coyunturalmente muy difíciles ${ }^{80}$. El corregidor de San Jerónimo, por caso, negoció con el alcalde primero de la ciudad en su propia casa-participó de una reunión del cabildo realizada allí- la obtención de un buen número de reses para sí y para el de San Javier como insumo para recoger a "las familias dispersas" ${ }^{81}$. Por lo informado en la misma reunión, se sabe que el recaudador de arbitrios debió pagarle a Larramendi casi 10 pesos que, según acusa, le insumió "el mantenimiento de los referidos indios", a los cuales parece haber alojado en su propia casa ${ }^{82}$.

A diferencia de los corregidores castellanos o indianos los corregidores indí-

${ }^{76}$ Moriconi, Miriam, Administración, cit. (n. 67), pp. 164-165.

${ }^{77} \mathrm{La}$ referencia de la carta del cura de San Pedro al corregidor de San Javier, en AGSF, AC, XIV, ff. 554-555, sesión del 11 de octubre de 1779.

${ }^{78}$ Como los caciques Manuel Nevedagna (mocoví) y Miguel Benavides (el abipón Ichoalay), corregidores de los pueblos San Francisco Javier y San Jerónimo respectivamente. AGSF, AC, XV, ff. 371-373, sesión del 11 de mayo de 1789.

${ }^{79}$ AGSF, AC, XVI, ff. 385-387. Lo mismo encuentra desde luego Sandra Díaz para los casos que analiza en las misiones guaraníes, p. 113. Los autores que la precedieron en el estudio de las misiones ya habían mostrado además cómo era el procedimiento de elección y sus competencias y atribuciones.

${ }^{80}$ En agosto de 1780 los corregidores de estos pueblos consiguieron 250 reses para cada pueblo amén de 18 caballos para 9 indios que andaban de a pie, así como 8 hachas para cada uno de los caciques. La operación fue puesta bajo la supervisión del capitán de milicias Manuel Roldán acompañado de 3 peones. AGSF, AC, XV, ff. 393-397, 1 de agoto de 1789.

${ }^{81}$ AGSF, AC, XV, f. 401, sesión del 4 de agosto de 1789.

${ }^{82}$ AGSF, AC, XV, ff. 411-412, sesión del10 de septiembre de 1789. 
genas de pueblos de indios no tenían jurisdicción, esto quiere decir sencillamente que no juzgaban. No lo habilitaba la autoridad hispánica, es cierto, pero sobre todo no ocurría porque la naturaleza de su forma de construcción de la autoridad y el liderazgo no lo contemplaba ${ }^{83}$. Esta situación fue recogida en relatos particularmente claros que, bajo la forma de una colección de cartas de viaje, publicó el ilustrado manchego Pedro Estala con gran éxito editorial entre 1795 y $1801^{84}$ : una descripción de las provincias del Paraguay probablemente redactada por dos religiosos franciscanos, señala que los pueblos de indios que había en la región -los "indios de paz" o "indios amigos", según sus propios términos- estaban organizados a semejanza de las ciudades y pueblos grandes de españoles: "En cada uno de los pueblos hay un Indio Corregidor, sin mas jurisdicción que el velar sobre la conducta de los demás, y hacer cumplir las órdenes del Cura y del Administrador de los bienes del pueblo. Hay además dos Alcaldes y los demás oficios de Cabildo: así estos como el Corregidor, se eligen por influxo del Cura, que conoce el talento de sus indios, pero los confirma después el Gobernador de la provincia [...]"85.

La visión del viajero, montada sobre la experiencia de las misiones guaraníticas, coincide con las descripciones de Cardiel, Charlevoix y Escandón citadas por Sandra Díaz, quien agrega -de la mano de Nusdorfer- la existencia de algunos corregidores abiertamente rebeldes, que hicieron asambleas y se contactaron por escrito con pares de sus pueblos en calidad de gobernadores temporales por encargo del rey ${ }^{86}$.

El corregidor se consolidó como forma institucionalizada de autoridad indígena de los pueblos de indios establecidos en Santa Fe durante la segunda mitad del siglo XVIII y, en tal calidad, sobrevivió todos los cambios institucionales acaecidos desde su primera aparición -incluyendo la Revolución, la autonomía provincial, los reglamentos de López e incluso la Carta Magna nacional y la provincial- más allá de la mitad del siglo XIX. Presumo que los pueblos que adoptaron esta figura en su organización pudieron mantenerla hasta su desaparición, pero es difícil comprobar qué sucedió en cada caso ${ }^{87}$.

\section{REFLEXIONES FINALES}

Quizás como consecuencia de la adopción de enfoques todavía más atentos a las fuentes prescriptivas que a la producida por la actividad de gobierno y justicia de los propios agentes en América, durante muchas décadas se construyó una

\footnotetext{
${ }^{83}$ LuCaioli, Carina, Abipones, cit. (n. 68), p. 188.

${ }^{84}$ Arenas Cruz, María Elena, Pedro Estala, vida y obra: una aportación a la teoría literaria del siglo XVIII español (Madrid, Consejo Superior de Investigaciones Científicas, 2003), p. 121.

${ }^{85}$ Estala Ribera, Pedro El viajero universal o noticia del mundo antiguo y nuevo (Madrid, Imprenta de Villalpando, 1797), XIV, p. 256 y 265.

${ }^{86}$ Díaz de Zappia, Sandra, Participación, cit. (n. 73), p. 115.

${ }^{87}$ Dalla-Corte Caballero, Gabriela, Franciscanos, mocovíes y colonos de la zona chaqueña de Santa Fe 1850-2011: el liderazgo de la mocoví Dora Salteño en Colonia Dolores (Rosario, Prohistoria-TEIAA, 2012), pp. 62-63, documenta la acción del cacique corregidor José Rojas en la decisión de repoblar Santa Rosa de los Calchines al final del gobierno de Rosendo Fraga (1858-1860).
} 
imagen donde los territorios americanos de la Monarquía hispánica aparecen retratados como un recipiente casi siempre pasivo (aunque en algunos casos también conflictivo $)^{88}$ de operaciones que describían una suerte de traslado transoceánico de un mundo institucional. Los conceptos empleados fueron diversos: John Elliott habló de una trasposición ${ }^{89}$, Adolfo García Gallo y Ricardo Levene utilizaron el de "transplante" ${ }^{90}$ y, más recientemente, Guillermo Céspedes del Castillo continuaba hablando de una "implantación" ${ }^{11}$ de instituciones políticas españolas en América. Y esto ha sido tematizado así básicamente por la necesidad de contar la instalación de un "Estado" en América".

Estas operaciones intelectuales se enfrentan con una dura realidad cuando pretenden ser documentadas, ya que en América, finalmente, todo es distinto. La solución adoptada suele transitar por apoyarse en que las experiencias americanas presentan siempre un rasgo particular o excepcional respecto de las reglas castellanas. El problema, en este punto, parece ser que esas historiografías no asumen jamás que dichas excepcionalidades se presentan con una frecuencia tal que las ha convertido en regla. Desde la posición que aquí se sostiene, creemos que en lugar de una versión bastarda ${ }^{93}$ de un modelo ideal debiera hablarse es de un modelo mezclado, que no es nativo (ni de Castilla ni de América) y cuyo intento de réplica nunca fue un calco. No hace falta la intervención del nativo

${ }^{88}$ Simpson, Lesley, The "encomienda", cit. (n. 54).

${ }^{89}$ Elliott, John, La conquista española y las colonias, en Bethell, Leslie (editor), Historia de América Latina (Barcelona, Crítica, 1990), I, p. 12.

${ }^{90}$ Sostenido por los historiadores del derecho indiano en clave de continuidad entre el derecho "español" y los derechos "patrios" latinoamericanos; véase al respecto DALLA-CorTE Caballero, Gabriela, La historia del derecho en la Argentina o la historia jurídica como proceso, en Prohistoria, 3 (Rosario, 1999), p. 149.

${ }^{91}$ Céspedes del Castillo, Guillermo, La organización institucional, en Historia General de América Latina, (París - Madrid, Ediciones UNESCO - Trotta, 2001), III: Consolidación del orden colonial, 1 , p. 30

${ }^{92}$ Pietschmann, Horst, El estado y su evolución al principio de la colonización española en América (1980, traducción al castellano de Angélica Scherp, México, Fondo de Cultura Económica, 1989); Les Indes de Castille, en AA.VV., Le premier âge de létat en Espagne (1450-1700) (Paris, Conseil Nationale de la Recherche Scientifique, 1989), pp. 148-188; El desarrollo estatal de Hispanoamérica: enfoques metodológicos, en Chrónica Nova, 21 (Granada, 1994), pp. 469-492; Los principios rectores de Organización Estatal en las Indias, en ANNINO, Antonio y otros, De los Imperios a las Naciones: Iberoamérica (Zaragoza, Ibercaja, 1994), pp. 75-103. Esto también se constata entre algunos historiadores del derecho: LEVENE, Ricardo, Historia del derecho argentino (Buenos Aires, Guillermo Kraft, 1945), I, pp. 33 y 109, hablaba del trasplante del "derecho y las instituciones hispánicas” que los Reyes Católicos habían hecho a Indias.

${ }^{93}$ La expresión "feudalismo bastardo", originalmente aplicada por K. B. MacFarlane en la década de 1940 para la Europa Moderna, no debe comprenderse como versión "degenerada" o "degradada" sino como "superficialmente similar". MACERA, Pablo, El feudalismo colonial americano: el caso de las haciendas peruanas, en Trabajos de historia (Lima, INC, 1977), III, pp. 139-227, ensayó explicaciones en este sentido ya no para las categorías jurídicas sino para un análisis de sistema, acuñando la categoría de feudalismo colonial americano. También lo hicieron Julio Castellanos y José Manuel Fernández en trabajos sobre Guatemala (1992), Carlos Lazo García y Alexander Izquierdo (1997). Este tipo de enfoque ha gozado de buena difusión también en la historia de la arquitectura, del urbanismo, de la religión y del arte. 
(americano) para asegurar que las circunstancias mismas del gobierno de la monarquía en América -distanciamiento físico, policentrismo jurídico y afirmación en los principios generales del gobierno hispánico ajustándolo a circunstancias particulares- permiten hablar de la creación de esquemas mestizos de gobierno.

Aceptando que la realidad americana pocas veces se ajustaba a la letra de las leyes hispánicas, los procedimientos de una historia institucional muy apegada a la historia del derecho tradicional, cuestionaban tácitamente la operación metodológica subyacente al conjunto explicativo de la historiografía más antigua que se apoyaba en las leyes de Indias para describir el marco institucional: ¿por qué tomar la legislación como fuente de datos si, finalmente, la realidad no devuelve sino una imagen deformada de ese supuesto ideal?

El enfoque desde el cual ha sido construido este trabajo, que por cierto en estos tiempos no podría caer en dicha trampa, tenía también la obligación de eludir el riesgo que supone caer en el otro extremo, magníficamente retratado por Tau Anzoátegui hace más de veinte años: "Durante las últimas décadas se difundió como tópico historiográfico la existencia de dos mundos separados, sin conexión entre sí: el de las leyes de una parte y el de los hechos sociales y económicos, de otra. [...] Se supuso entonces que las leyes carecían de efecto sobre esa vida cotidiana y por lo tanto fueron expulsadas del horizonte del historiador de la economía y de la sociedad [...]. En fin, el mundo de las leyes quedó asimilado a un universo ideal, opuesto al real, en una contraposición sin matizaciones"94.

Quedaba, por último, evitar la fácil tentación de caer en el regodeo inconducente de constatar la "tensión" entre normativa y práctica, versión posmoderna de las tesis de la implantación bastarda. Nuestra opción fue, por fin, la de asignar al derecho, al mundo jurídico en general y a los artificios institucionales un lugar positivo, considerándolo como parte de la producción de los agentes así como de los recursos disponibles que tenían para arbitrar situaciones que, dado que transitaron por estos carriles, dejaron huellas durables, verdaderas marcas en la historia de las técnicas del gobierno y la gestión negociada: instituciones practicables y practicadas, mestizas, sin importar el componente étnico de la mezcla. En este aspecto, la utilización de esta figura en los procesos de equipamiento del territorio en la jurisdicción santafesina es mestiza (en su acepción más fuerte, la de mezclada) tanto cuando el corregidor hispano-criollo reemplaza a la figura del teniente de gobernador como cuando en los pueblos de indios se designan corregidores indígenas.

A pesar de la cercanía de provincias organizadas en corregimientos, incluso durante el periodo de la Primera Audiencia de Buenos Aires la experiencia santafesina muestra que el cambio de nombre no alteró la función y que los corregidores fueron percibidos como tenientes del gobernador. Este trabajo trató, finalmente, abonar a una propedéutica contra las generalizaciones que pretenden hacer de aquello que materializó en las áreas nucleares de la conquista puede, metoními-

${ }^{94}$ Tau AnZoÁtegui, Víctor, La ley en la América Hispana, del descubrimiento a la emancipación (Buenos Aires, Instituto de Investigaciones de Historia del Derecho, 1992, p. 3. 
camente, convertirse en un universal indiano tanto como agregar evidencia local a retratos generales que intentaron hacer justicia a estas variaciones ${ }^{95}$.

Según lo que se ha mostrado en este estudio, el carácter mestizo de la figura del corregidor en la experiencia santafesina, incluye pero excede completamente la cuestión étnica. De manera que, así como la categoría de mestizaje es válida para referirse a los procesos donde se mezclan seres vivos e imaginarios, parece legítimo pensar también en esta dimensión las instituciones de gobierno y el equipamiento del territorio, sin lugar a dudas una parte imprescindible de nuestras culturas.

\section{BiBLIOGRAFÍA}

Altamira y Crevea, Rafael, Autonomía y descentralización legislativa en el Régimen colonial español. Siglos XVI y XVIII (Buenos Aires, Instituto de Investigaciones de Historia del Derecho, 2011).

Arenas Cruz, María Elena, Pedro Estala, vida y obra: una aportación a la teoría literaria del siglo XVIII español (Madrid, CSIC, 2003).

Assadourian, Carlos, El sistema de la economía colonial (Lima, IEP, 1982).

BARRIERA, Darío G., Entre el retrato jurídico y la experiencia en el territorio. Una reflexión sobre la función distancia a partir de las normas de los Habsburgo sobre las sociabilidades locales de los oidores americanos, en Caravelle, 101 (Toulouse, dic. de 2013).

BARRIERA, Darío G., La organización del territorio y su gobierno: alcaldes mayores para la villa del Rosario. Un capitulo de transición (1826-1832), en Revista de la Junta Provincial de Estudios Históricos de Santa Fe, 70 (Santa Fe, 2012).

Barriera, Darío, Resistir al Teniente con la letra del Rey: la conflictiva relación del Cabildo de Santa Fe con la Gobernación del Río de la Plata, años 1620, en DALLA CORTE, Gabriela y otros (coordinadores), X Encuentro Debate América Latina Ayer y Hoy: homogeneidad, diferencia y exclusión en América (Barcelona, Universidad de Barcelona, 2006).

Bermúdez Aznar, Agustín, El corregidor en Castilla durante la Baja Edad Media (1348-1474) (Murcia, 1974).

Castillo de Bovadilla, Jerónimo, Política para corregidores y señores de vasallos, en tiempos de pazy de guerra (1599, Amberes, 1704).

Cauzzi, Teresa, Historia de la Primera Audiencia de Buenos Aires (1661-1672) (Rosario, Universidad Católica Argentina, 1984).

Céspedes del CAStillo, Guillermo, La organización institucional, en Historia General de América Latina, (París - Madrid, Ediciones UNESCO - Trotta, 2001), III: Consolidación del orden colonial, 1.

Covarrubias, Sebastián de, Tesoro de la lengua castellana o española (1611, Barcelona, Alta Fulla, 1998).

\footnotetext{
${ }^{95}$ En esta descripción, por ejemplo, los tenientes de gobernador no figuran como cabeza de los cabildos: "Estos alcaldes mayores o corregidores, supeditados directamente a los virreyes, presidentes, gobernadores y capitanes generales, según los casos, representaron, en la ciudad en que ejercieron sus funciones de gobierno, el poder inmediatamente superior y con frecuencia tuvieron conflictos jurisdiccionales con los cabildos municipales y con sus alcaldes ordinarios": Ots Capdequí, José María, El estado, cit. (n. 3), p. 75.
} 
Cruz Barney, Óscar, Derecho indiano local: el reglamento provisional para las milicias del Real del Mazapil de 1786, en AMHD., 22 (México, 2010).

Dalla-Corte Caballero, Gabriela, Franciscanos, mocovies y colonos de la zona chaqueña de Santa Fe 1850-2011: el liderazgo de la mocoví Dora Salteño en Colonia Dolores (Rosario, Prohistoria-TEIAA, 2012).

Dalla-Corte Caballero, Gabriela, La historia del derecho en la Argentina o la historia jurídica como proceso, en Prohistoria, 3 (Rosario, 1999).

DíAZ de ZAPPIA, Sandra, Participación indígena en el gobierno de las reducciones jesuíticas de guaranies, en Revista de Historia del Derecho, 31 (Buenos Aires, 2003).

ElLIOTT, John, La conquista española y las colonias, en BeTHell, Leslie (editor), Historia de América Latina (Barcelona, Crítica, 1990), I.

EsCRICHE, Joaquín de, Diccionario razonado de legislación y jurisprudencia (Nueva edición corregida notablemente y aumentada con nuevos artículos, notas y adiciones sobre el derecho americano por don Juan B. Guim, doctor en ambos derechos y abogado de los tribunales de España, París, Librería de Rosa, 1851).

Estala Ribera, Pedro El viajero universal o noticia del mundo antiguo y nuevo (Madrid, Imprenta de Villalpando, 1797), XIV.

Farberman, Judith Santiago del Estero y sus pueblos de indios. De las ordenanzas de Alfaro (1612) a las guerras de Independencia, en Andes, 19 (Salta, 2008).

GarCía Gallo, Alfonso, Alcaldes mayores y corregidores en Indias, en Estudios de derecho indiano (Madrid, 1972).

Gehrard, Peter, Geografía histórica de la Nueva España, 1519-1821 (México, Universidad Nacional Autónoma de México, 1986).

GonzÁlez Alonso, Benjamín, El corregidor castellano (1348-1808) (Madrid, Siglo XXI, 1970).

Levene, Ricardo, Historia del derecho argentino (Buenos Aires, Guillermo Kraft, 1945), I.

Lohmann Villena, Guillermo, El corregidor de indios en el Perú bajo los Austrias (Lima, Pontificia Universidad Católica del Perú, 2001).

Lohmann Villena, Guillermo, La nueva estructura política, en Pease, Franklin - Frank MoYa PONs (directores), El primer contacto y la formación de nuevas sociedades. Historia General de América Latina (Madrid, Unesco - Trotta), II.

LORANDI, Ana María, El servicio personal como agente de desestructuración en el Tucumán colonial, en Revista Andina, 6 (Cuzco, 1988).

LuCAIOLI, Carina, Abipones en las fronteras del Chaco. Una etnografía histórica sobre el siglo XVIII (Buenos Aires, Sociedad Argentina de Antropología, 2011).

Macera, Pablo, El feudalismo colonial americano: el caso de las haciendas peruanas, en Trabajos de historia (Lima, INC, 1977), III.

Martínez Alcubilla, Marcelo Diccionario de administración (Madrid, imprenta propia, 1858).

Mitre, Emilio, La extensión del régimen de corregidores en el reinado de Enrique III de Castilla (Valladolid, 1969).

MONLAu, Pedro Felipe Diccionario etimológico de la lengua castellana (Madrid, Imprenta de Rivadeneyra, 1856). Corominas, Joan, Diccionario crítico etimológico castellano e hispánico (Madrid, Gredos, 1984), II.

Moriconi, Miriam, Administración borbónica de pueblos de indios en el Río de la Plata. Matrículas de pueblos de Santa Fe (1785), en Prohistoria, 18 (Rosario, 2012). 
Ots Capdequí, José María, El estado español en las indias (México, Fondo de Cultura Económica, 1957).

PAUCKE, Florian, Hacia allá y para acá, Memorias (traducción al castellano de Edmundo Wernicke y edición de Agustín Alzari, Santa Fe, Ministerio de Innovación y Cultura, 2010).

Pazos, María Luisa, El Ayuntamiento de la ciudad de México en el siglo XVII. Continuidad institucional y cambio social (Diputación de Sevilla, Sevilla, 1999).

Pietschmann, Horst, El desarrollo estatal de Hispanoamérica: enfoques metodológicos, en Chrónica Nova, 21 (Granada, 1994).

Pietschmann, Horst, El estado y su evolución al principio de la colonización española en América (1980, traducción al castellano de Angélica Scherp, México, Fondo de Cultura Económica, 1989).

Pietschmann, Horst, Les Indes de Castille, en AA.VV., Le premier âge de létat en Espagne (1450-1700) (Paris, Conseil Nationale de la Recherche Scientifique, 1989).

Pietschmann, Horst, Los principios rectores de Organización Estatal en las Indias, en Annino, Antonio y otros, De los Imperios a las Naciones: Iberoamérica (Zaragoza, Ibercaja, 1994).

Salinas, María Laura, Encomienda, trabajo y servidumbre indigena en Corrientes. Siglos XVII-XVIII (Tesis de Maestría, Universidad Internacional de Andalucía, La Rábida, 2008).

Sanjurjo, Iné, Los corregidores de la Provincia de Cuyo y sus agitadas relaciones con el cabildo de Mendoza (1748-1784), en Richard-Jorba, Rodolfo - Marta S. BonAudo (coordinadores), Historia Regional. Enfoques y articulaciones para complejizar una historia nacional (La Plata, UNLP, 2014).

SiCA, Gabriela, Transformaciones y formas de legitimación en la autoridad de los caciques coloniales de Jujuy. Siglo XVII, en Memoria Americana, 17 (Buenos Aires, 2009).

Simpson, Lesley Byrd, The "encomienda" in New Spain. The Beginning of Spanish Mexico (Berkeley, University of California Press, 1966).

Stein, Stanley J. - SteIn, Barbara H. La herencia colonial de América Latina (1970, México, Siglo XXI, 1970).

Tau AnzoÁtegui, Víctor, La ley en la América Hispana, del descubrimiento a la emancipación (Buenos Aires, Instituto de Investigaciones de Historia del Derecho, 1992).

Thomas, Yan, El artificio de las instituciones (Buenos Aires, Ediciones de la Universidad de Buenos Aires, 1999).

Trujillo, Oscar J., Consenso, negociación y conflicto en la Monarquía Hispánica: La élite de Buenos Aires en el XVII (Tesis de doctorado, Luján, Univ. Nacional de Luján, 2013, inédita).

Zavala, Silvio, La encomienda indiana (México, Editorial Porrúa, 1973).

ZorRaQuín BeCú, Ricardo, La organización politica argentina en el periodo hispánico (1959, $3^{a}$ edición, Buenos Aires, Abeledo Perrot, 1967). 